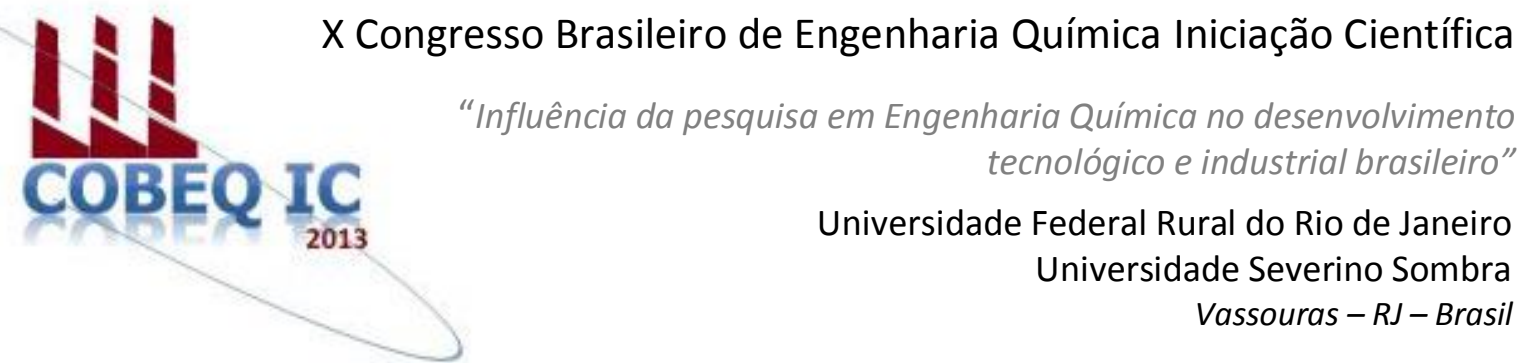

\title{
EXTRAÇÃO DE LÍPIDIOS DE MICROALGA: AVALIAÇÃO DA QUALIDADE UTILIZANDO ESPECTROSCOPIA DE INFRAVERMELHO FT-IR
}

\author{
PINHEIRO $^{* 1}$, C.P.; INSOGNIA ${ }^{2}$, A.; STRIEDER ${ }^{1}$, M.M.; \\ POHNDORF ${ }^{3}$, R.S.; PINTO ${ }^{4}$, L.A.A. \\ ${ }^{1}$ Aluno de Engenharia de Alimentos - EQA/FURG; ${ }^{2}$ Aluno de Engenharia Química; ${ }^{3}$ Doutorando \\ LOU/EQA/FURG; ${ }^{4}$ Docente EQA/FURG. \\ Escola de Química e Alimentos - Universidade Federal Rural do Rio Grande \\ Endereço - Rua engenheiro Alfredo Hulk, 476, Rio grande, CEP. 96203-900, RS, \\ email: dqmpinto@furg.br
}

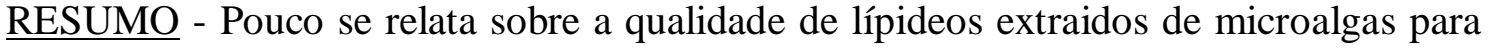
obtenção de biocombustíveis. Assim, o objetivo deste trabalho foi extrair lipídios a partir da biomassa seca da microalga Spirulina sp. LEB 18 utilizando os seguintes métodos: (A) Bligh e Dyer, (B) Folch, (C) Soxhlet utilizando álcool isopropílico e vácuo, (D) Soxhlet utilizando álcool isopropílico sem vácuo, (E) Soxhlet utilizando hexano e vácuo e (F) Soxhlet utilizando hexano sem vácuo. O teor de lipídios foi obtido gravimetricamente e sua qualidade verificada através de análise de infravermelho com transformada de Fourier (FTIR-ATR). Os resultados indicaram que o método D foi o mais eficiente para extração, apresentando teor de lipídios de 10,3\%. Os espectros de infravermelho mostraram que bandas características de triglicerídeos foram observadas nos lipídios independente do método de extração. A banda em $3350 \mathrm{~cm}^{-1}$, correspondente ao estiramento dos grupos ligados ao hidrogênio $\mathrm{O}-\mathrm{H}$ e N-H, bem como a banda em $1650 \mathrm{~cm}^{-1}$ proveniente de carbonos constituintes de anéis aromáticos, não foram identificadas para as amostras extraídas nos métodos E e F. Esses resultados mostraram que o produto extraído pelos métodos $\mathrm{E}$ e $\mathrm{F}$ foi mais seletivo em relação a extração de triglicerídeos.
\end{abstract}

Palavras chave: Spirulina, Soxhlet, Folch.

\section{INTRODUÇÃO}

As algas são organismos fotossintetizantes, que utilizam luz solar e gás carbônico para produzir biomassa. Podem ser cultivadas em tanques ou em terras não aráveis, sem competir com alimentos (Singht e $\mathrm{Gu}$, 2010). As microalgas apresentam potencial de produzir uma grande quantidade de biomassa, superior a maioria das culturas atuais.

As microalgas têm sido investigadas como fonte para produção de biocombustíveis, alimento, ração e compostos bioativos. Em comparação com culturas agrícolas tradicionais possuem elevada produtividade de lipídios, proteínas e carboidratos. Devido à demanda crescente por alimentos e fontes 
alternativas de energia, os lipídios de microalga têm despertado interesse por serem ricos em ácidos graxos insaturados de cadeia longa (Ryckebosch et al., 2012).

As microalgas contêm diversos compostos bioativos associados à prevenção de doenças. Compostos fenólicos e carotenóides possuem caráter antioxidante e atuam na prevenção de câncer e doenças cardiovasculares. Ácidos graxos poliinsaturados de cadeia longa (ômega 3), também estão associados a prevenção de doenças cardiovasculares. Esteróis possuem papel importante na diminuição dos níveis de colesterol LDL e atividade antiinflamatória (Francavilla et al., 2010; Zuliani et al., 2009; Plaza et al., 2009).

Pigmentos naturais como ficocianina, luteína e betacaroteno são produzidos em microalgas (Mary Leema et al., 2010) e apresentam grande interesse comercial em detrimento ao uso de pigmentos sintéticos, principalmente quando se tratam de remédios, alimentos e cosméticos.

A produção de óleo de microalgas apresenta grande interesse mundial para obtenção de biocombustível devido a sua alta produtividade. Em comparação com outras culturas como a soja, a microalga produz aproximadamente 100 vezes mais óleo por unidade de área, além de elevada taxa de crescimento da biomassa (Chisti, 2007).

A obtenção de óleo de microalga em grande escala depende principalmente de viabilidade econômica e de avanços nas técnicas de produção de biomassa, extração de lipídios, refino e aspectos de engenharia. Diversos fatores interferem na extração de lipídios de microalgas, como o tipo de solvente utilizado, tamanho de partícula, métodos de ruptura celular e secagem da biomassa (Balasubramanian et al., 2013).

Assim, o objetivo neste trabalho foi extrair lipídios a partir da biomassa seca da microalga Spirulina sp. LEB-18 utilizando diferentes métodos e solventes. A qualidade dos lipídios foi investigada através da análise de infravermelho.

\section{MATERIAL E MÉTODOS}

A microalga Spirulina sp. LEB-18 foi cultivado segundo Costa et al., (2004) em fotobiorreatores de $450 \mathrm{~L}$ ao ar livre, sob condições não controladas, no sul do Brasil. Durante estes cultivos, a água foi suplementado com 20\% de meio Zarrouk (Zarrouk, 1966). A concentração inicial da biomassa foi de 0,15 g. $\mathrm{L}^{-1}$. Amostras foram retiradas a cada $24 \mathrm{~h}$ para determinar a biomassa concentração por meio de medições da densidade óptica em $670 \mathrm{~nm}$ usando um espectrofotômetro (modelo Quimis Q108DRM, São Paulo, Brasil). No final do período de cultivo, a biomassa foi obtida por filtração e prensagem.

A microalga contendo $79,2 \%$ de umidade foi secada segundo Oliveira et al., (2010), utilizado secador de bandejas descontínuo com velocidade do ar quente de 2,5 m.s ${ }^{-1}$ e densidade de carga de $4 \mathrm{~kg} \cdot \mathrm{m}^{-2}$. Foi empregada temperatura de $60^{\circ} \mathrm{C}$, espessura da amostra de $5 \mathrm{~mm}$ e tempo de 210 minutos. Após a secagem o produto foi triturado num moinho de facas (modelo Willey, Filadélfia, EUA) e embalado em recipientes de vidro, ermeticamente fechado e mantido em temperatura de $8^{\circ} \mathrm{C}$. A umidade final da microalga foi de $8,3 \%$.

Os métodos de extração testados foram os seguintes: (A) Bligh e Dyer (1959), utilizando mistura de clorofórmio:metanol (1:1 v/v); (B) Folch (1957), utilizando mistura clorofórmio:metanol $(2: 1 \mathrm{v} / \mathrm{v})$; (C) soxhlet utilizando álcool isopropílico e vácuo, (D) Soxhlet utilizando álcool isopropílico sem vácuo, (E) Soxhlet utilizando hexano e vácuo e (F) Soxhlet utilizando hexano sem vácuo.

As extrações utilizando aparato soxhlet foram realizadas com $5 \mathrm{~g}$ de biomassa e 150 $\mathrm{ml}$ de solvente durante $6 \mathrm{~h}$. Uma bomba de vácuo foi acoplado ao sistema, utilizando 0,08 $\mathrm{MPa}$. Após a extração o solvente foi recuperado. Para quantificação, as amostras foram conduzidas a estufa com temperatura de $105^{\circ} \mathrm{C}$ por $1 \mathrm{~h}$, para eliminação de resíduos de solvente. Após alcançar a temperatura ambiente, em dessecador, o teor lipídico foi obtido gravimetricamente. As extrações foram feitas em duplicata. 
A qualidade dos lipídios extraídos foi verificada através de análise de infravermelho com refletância total atenuada (FTIR-ATR) (Prestige 21, 210045, Japão).

\section{RESULTADOS E DISCUSSÃO}

Dos métodos testados como mostra a Figura 1, o método analítico de Folch (B) apresentou teor lipídico de $8,9 \%$ e o método Bligh e Dyer (A) aproximadamente metade deste valor. Iverson (2001), comparando os métodos para tecidos marinhos observou que para amostras com teor de lipídios acima de $2 \%$ o método de Bligh e Dyer subestima o resultado. A causa desta diminuição é atribuída à relação entre solvente e amostra e a proporção de clorofórmio para metanol.

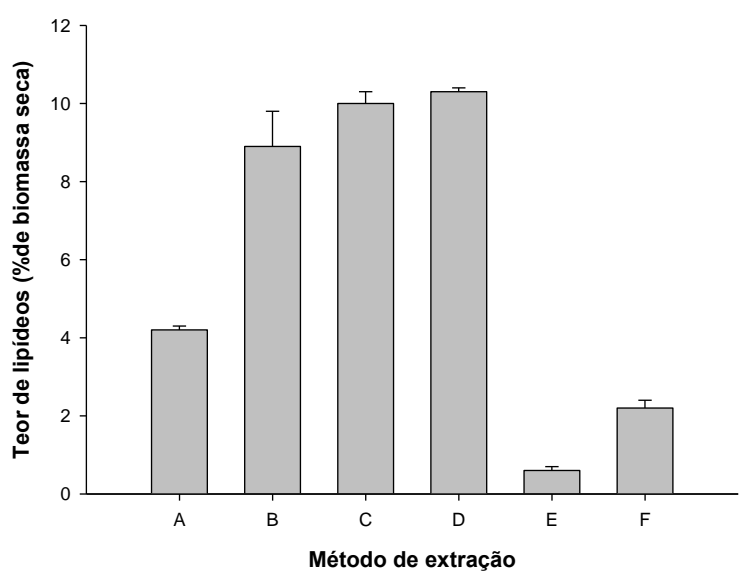

Figura 1 - Teor de lipídios de microalga Spirulina obtida por diferentes métodos.

O maior teor de lipídios foi encontrado com álcool isopropílico sem a utilização de vácuo (D), 10,3\%. O álcool isopropílico extrai ambos os lipídios polares e neutros eficientemente. As microalgas apresentam quantidades mais elevadas de lipídios polares quando comparado com outros óleos. Em microalgas com potencial para produção de biodiesel, a quantidade de triacilgliceróis varia entre 40 e $70 \%$ (Wang e Wang, 2012).

A interferência do vácuo foi observada quando se empregou hexano como solvente, reduzindo significativamente o rendimento de extração (E). Isto pode ser explicado pela diminuição da temperatura de ebulição do solvente para aproximadamente $35{ }^{\circ} \mathrm{C}$. A extração com hexano em temperatura de condensação, próximo a $68{ }^{\circ} \mathrm{C}(\mathrm{F})$ apresentou teor de lipídios de 2,2\%. Para extração de lipídios da microalga Spirulina, Zheng (2012) testou diferentes solventes. A extração com hexano apresentou o menor teor de lipídios, apenas $1,88 \%$, atribuindo este resultado à baixa polaridade do solvente. Além disso, a maior eficiência de extração proporcionou maiores quantidades de pigmentos. Andrich (2006) estudando a mesma espécie de microalga encontrou o valor de 7,8\% extraído em Soxhlet com hexano. Este aumento pode estar relacionado com diferenças no cultivo e com o tipo de ruptura celular da amostra.

As Figuras 2 e 3 apresentam os espectros do extrato lipídico obtido com álcool isopropílico com e sem a presença de vácuo, respectivamente. Poucas diferenças são observadas entre os espectros. Entretanto, quando comparamos com os outros métodos de extrações, algumas diferenças podem ser notadas. As bandas em 3550 e $3150 \mathrm{~cm}^{-1}$, são em relação ao alongamento $\mathrm{O}-\mathrm{H}$. A banda de $1100 \mathrm{~cm}^{-1}$ pode ser atribuída a um alongamento C-O. A banda próxima a 1650 $\mathrm{cm}^{-1}$ pode estar relacionada com a presença de anéis aromáticos. Estas diferenças nas extrações (E) e (F) indicam uma maior presença de compostos fenólicos e pigmentos na amostra.

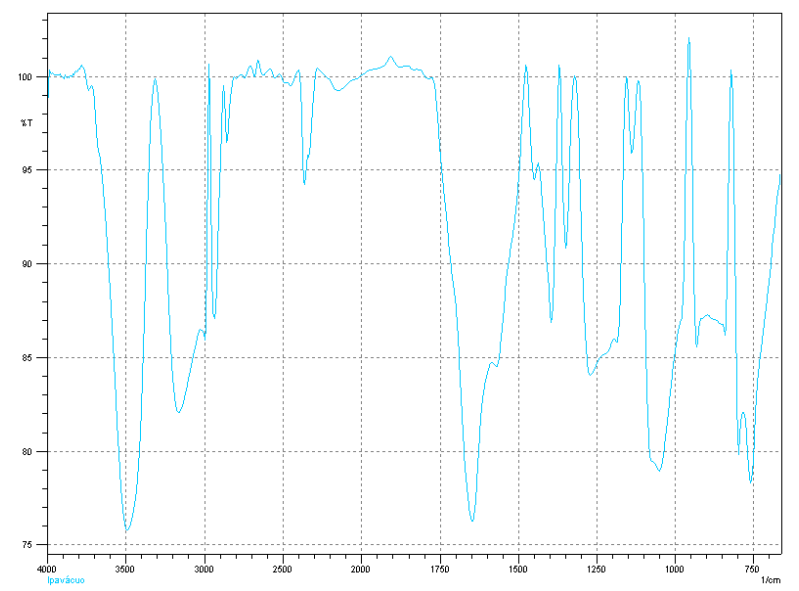

Figura 2 - Espectro FTIR de lipídios de microalga, extraído com álcool isopropílico e vácuo $(C)$.

Uma grande quantidade de compostos polares está presente na amostra, entretanto algumas 
bandas características de triacilgliceróis podem ser observadas ou estão sobrepostas por outras bandas na extração com álcool isopropílico.

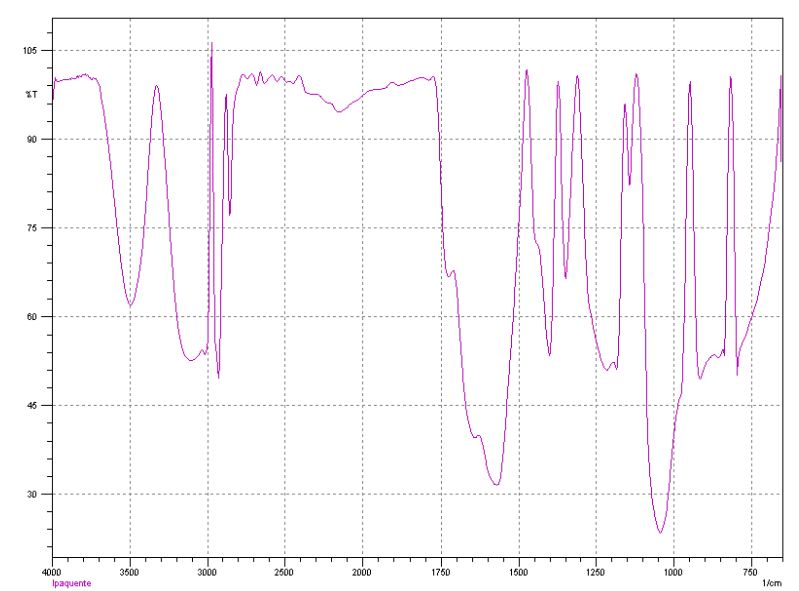

Figura 3 - Espectro FTIR de lipídios de microalga, extraído com álcool isopropílico sem vácuo $(C)$.

Como mostra a Figura 4, o espectro apresentado corresponde ao extrato lipídico extraído pelo método analítico de Foch (B).

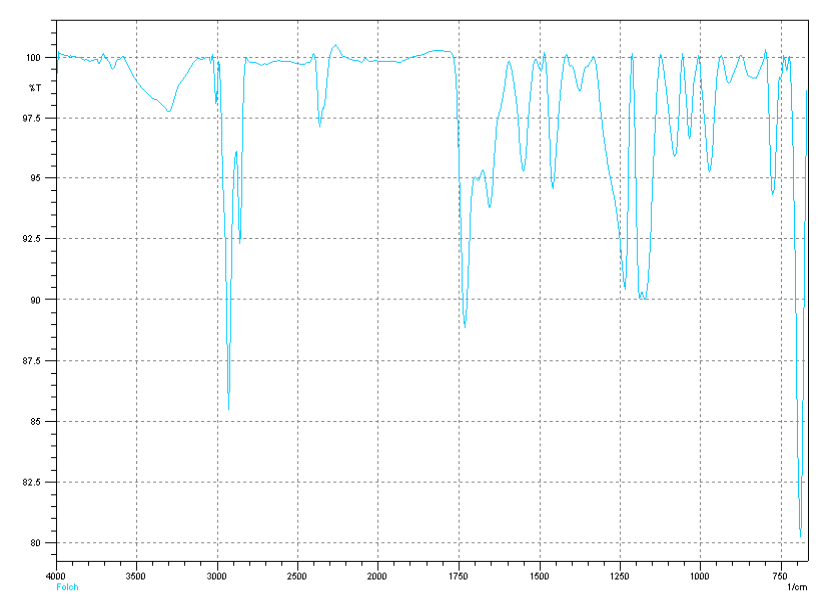

Figura 4 - Espectro FTIR de lipídios de microalga, extraído pelo método de Folch (B).

A banda centrada em $3350 \mathrm{~cm}^{-1}$, na Figura 4, corresponde ao estiramento dos grupos ligados ao hidrogênio $\mathrm{O}-\mathrm{H}$ e $\mathrm{N}-\mathrm{H}$, indicando a presença proteínas. As bandas comuns aos triacilgliceróis foram observadas.

Espectro semelhante ao de Folch (B), porém com bandas mais intensas, foi notado na extração pelo método de Bligh e Dyer (A) (Figura 5). Em ambas as extrações (A) e (B), destacou-se ma banda em $1240 \mathrm{~cm}^{-1}$, correspondendo ao estiramento $\mathrm{P}=\mathrm{O}$ que podem estar ligados a presença em maior quantidade de fosfolipídios.

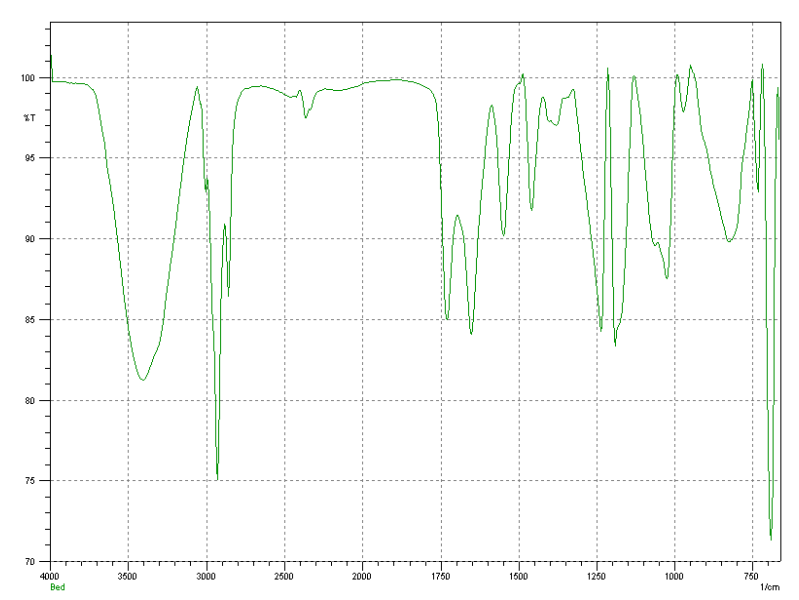

Figura 5 - Espectro FTIR de lipídios de microalga, extraído pelo método de Bligh e Dyer (A).

$\mathrm{Na}$ extração com hexano sem a utilização de vácuo (F) observou-se uma diminuição na presença de pigmentos como clorofila e ficocianina além de outros compostos polares, por meio dos espectros de infravermelho como mostra a Figura 6.

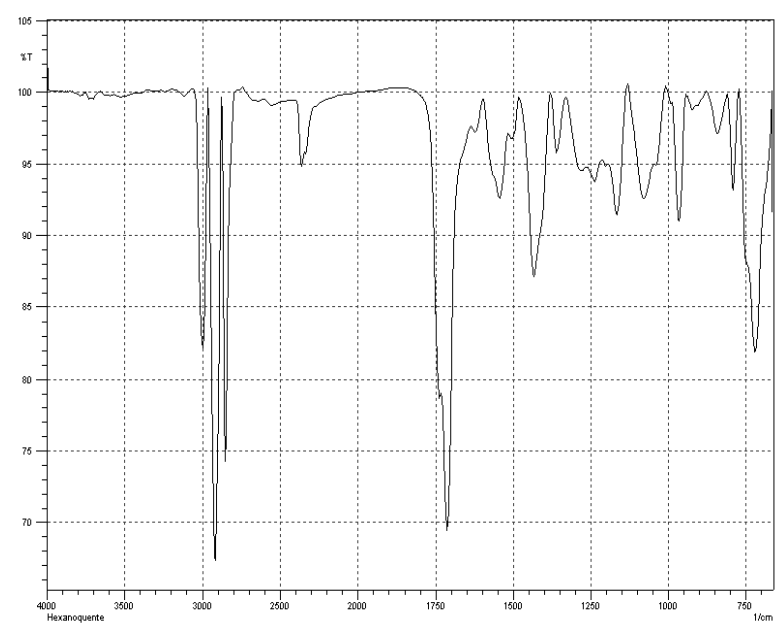

Figura 6 - Espectro FTIR de lipídios de microalga, extraído com hexano sem a presença de vácuo $(\mathrm{F})$.

A banda em $1745 \mathrm{~cm}^{-1}$ está relacionada com $(\mathrm{C}=\mathrm{O})$ dos triacilglicerois, de quem corresponde o estiramento $\mathrm{C}-\mathrm{O}-\mathrm{C}$ observado em $1160 \mathrm{~cm}^{-1}$. A banda $3008 \mathrm{~cm}^{-1}$ corresponde ao estiramento vibracional $\mathrm{C}-\mathrm{H}$ das bandas 
duplas cis $(=\mathrm{CH})$. A banda $1655 \mathrm{~cm}^{-1}$ está associada ao estiramento vibracional das bandas duplas carbono-carbono $(\mathrm{C}=\mathrm{C})$. Assim, confirmou-se a presença de triacilgliceróis.

Poucas diferenças foram observadas da extração (F) para a extração (E), com utilização de hexano e vácuo como mostra a Figura 7.

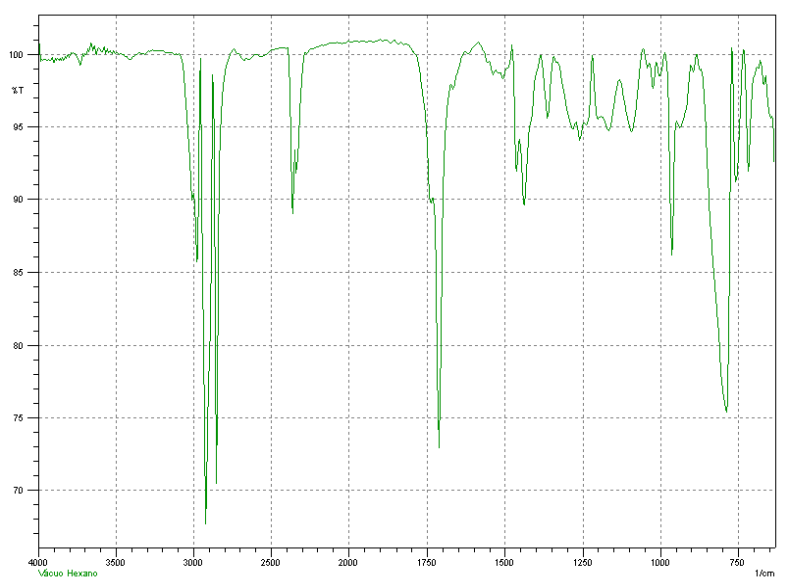

Figura 7 - Espectro FTIR de lipídios de microalga, extraído com hexano sem a presença de vácuo $(\mathrm{E})$.

A menor temperatura empregada nesta extração, por ocasião do vácuo, pode ser responsável por extrair menor quantidade de compostos como clorofila e ficocianina. Assim, a diminuição da banda $1549 \mathrm{~cm}^{-1}$, correspondendo à interação angular $\mathrm{N}-\mathrm{H}$, indica uma possível menor concentração de proteína e corantes na amostra.

\section{CONCLUSÃO}

A utilização de vácuo diminuiu o teor lipídico principalmente quando se utilizou hexano como solvente. O método de Folch extraiu um teor maior de lipídios do que o método de Bligh e Dyer. A utilização de álcool isopropílico como solvente proporcionou o maior teor de lipídios entre os métodos, entretanto a presença de compostos polares foi observada. O solvente hexano mostrou-se mais seletivo para extração de lipídios neutros, indicando a presença de triacligliceróis.

\section{REFERÊNCIAS}

ANDRICH, G.; ZINNAI, A.; NESTI, U.; VENTURI, F.; FIORENTINI, R. "Supercritical fluid extraction of oil from microalga spirulina (arthrospira) platensis". Acta alimentaria, v. 35 (2), p. 195-203, 2006.

BALASUBRAMANIAN, R. K.; DOAN, T. T. Y.; OBBARD, J. P. "Factors affecting cellular lipid extraction from marine microalgae". Chemical Engineering Journal, v. 215-216, p. 929-936, 2013.

BLIGH, E.G., DYER, W.M. "A rapid method of lipid extraction and purification". Can. J. Biochem. Physiol, v. 37, p. 911-917, 1959.

CHISTI, Y. "Biodiesel from microalgae. Biotechnol. Adv., v. 25, p. 294-306, 2007.

COSTA, J.A.V., COLLA, L.M. \& DUARTE FILHO, P.F. "Improving Spirulina platensis biomass yield using a fed-batch process". Bioresource Technology, v. 92, p. 237-241, 2004.

OLIVEIRA E.G.; DUARTE, J.H.; MORAES, K.; CREXI, V.T.; PINTO, L.A.A. "Optimisation of Spirulina platensis convective drying: evaluation of phycocyanin loss and lipid oxidation". International Journal of Food Science and Technology, v. 45, p. 1572-1578, 2010.

FOLCH, J.; LEES, M.; SLOANE STANLEY, G. H. "A simple method for isolation and purification of total lipids from animal tissues". The Journal of Biological Chemistry, v. 226, p. 497-509, 1957.

FRANCAVILLA, M., P. TROTTA, R. LUQUE. "Phytosterols from Dunaliella tertiolecta and Dunaliella salina : a potentially novel industrial application". Bioresource Technology, v. 101, p. 41444150, 2010

IVERSON, S. J.; LANG, S. L. C.; COOPER, M. H. "Comparison of the Bligh e Dyer and Folch Methods for Total Lipid Determination 
in a Broad Range of Marine Tissue". Lipids, v. 36, n. 11, 2001.

MARY LEEMA. J.T.; KIRUBAGARAN, R.; VINITHKUMAR, N.V.; DHEENAN, P.S.; KARTHIKAYULU, S. "High value pigment production from Arthrospira (Spirulina) platensis cultured n seawater". Bioresource Technology, v. 101, p. 9221-9227, 2010.

PLAZA, M., M. HERRERO, A. CIFUENTES, E. IBAÑEZ. "Innovative natural functional ingredients from Microalgae. Journal of Agricultural and Food Chemistry", v. 57, p. 7159-7170, 2009.

RYCKEBOSCH, E.; MUYLAERT, K.; FOUBERT, I. Optimization of an Analytical Procedure for Extraction of Lipids from Microalgae. Journal of American Oil Chemistry Society. V 89, p. 89-198, 2012.

SINGH, J.; GU, S. "Commercialization potential of microalgae for biofuels production". Renewable and Sustainable Energy Reviews, v. 14, p. 2596-2610, 2010.

WANG, G.; WANG T. "Characterization of Lipid Components in Two Microalgae for Biofuel Application”. J. Am. Oil Chem. Soc. V. 89, p. 135-143, 2012.

\section{ZARROUK, C. CONTRIBUTION A L'ÉTUDE D'UNE CYANOPHYCÉE. "Influence De Divers Facteurs Physiques Et Chimiques Sur La Croissance Et La Photosyntheèse De Spirulina Maxima". Ph.D. Thesis. Paris, France: University of Paris. 1966.}

ZHENG , G.; LI, C.; GUO, L.; RUO, W.; WANG, S. "Purification of Extracted Fatty Acids from the Microalgae Spirulina". J. Am. Oil Chem. Soc. v. 89, p. 561-566, 2012.

ZULIANI, G., M. GALVANI, E. LEITERSDORF, S. VOLPATO, M. CAVELIERI, R. FELLIN. "The role of polyunsaturated fatty acids (PUFA) in the treatment of dyslipidemias". Current Pharmaceutical Design, v. 15, p. 4173-4185, 2009. 